NASA/TM-2000-210250

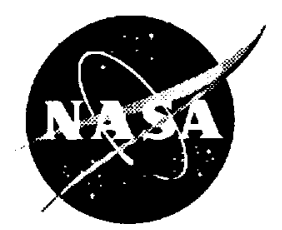

\title{
Experimental Replication of an Aeroengine Combustion Instability
}

J.M. Cohen, J.R. Hibshman, W. Proscia, T.J. Rosfjord and B.E. Wake

United Technologies Research Center, East Hartford, Connecticut

J.B. McVey

jbScienceS, Glastonbury, Connecticut

J. Lovett and M. Ondas

Pratt \& Whitney, West Palm Beach, Florida

J. DeLaat and K. Breisacher

Glenn Research Center, Cleveland, Ohio 
The NASA STI Program Office ... in Profile

Since its founding, NASA has been dedicated to the advancement of aeronautics and space science. The NASA Scientific and Technical Information (STI) Program Office plays a key part in helping NASA maintain this important role.

The NASA STI Program Office is operated by Langley Research Center, the Lead Center for NASA's scientific and technical information. The NASA STI Program Office provides access to the NASA STI Database, the largest collection of aeronautical and space science STI in the world. The Program Office is also NASA's institutional mechanism for disseminating the results of its research and development activities. These results are published by NASA in the NASA STI Report Series, which includes the following report types:

- TECHINICAL PUBLICATION. Reports of completed research or a major significant phase of research that present the results of NASA programs and include extensive data or theoretical analysis. Includes compilations of significant scientific and technical data and information deemed to be of continuing reference value. NASA's counterpart of peerreviewed formal professional papers but has less stringent limitations on manuscript length and extent of graphic presentations.

- TECHNICAL MEMORANDUM. Scientific and technical findings that are preliminary or of specialized interest, e.g., quick release reports, working papers, and bibliographies that contain minimal annotation. Does not contain extensive analysis.

- CONTRACTOR REPORT. Scientific and technical findings by NASA-sponsored contractors and grantees.
- CONFERENCE PUBLICATION. Collected papers from scientific and technical conferences, symposia, seminars, or other meetings sponsored or cosponsored by NASA.

- SPECIAL PUBLICATION. Scientific, technical, or historical information from NASA programs, projects, and missions, often concerned with subjects having substantial public interest.

- TECHNICAL TRANSLATION. Englishlanguage translations of foreign scientific and technical material pertinent to NASA's mission.

Specialized services that complement the STI Program Office's diverse offerings include creating custom thesauri, building customized data bases, organizing and publishing research results ... even providing videos.

For more information about the NASA STI Program Office, see the following:

- Access the NASA STI Program Home Page at http://www.sti.nasa.gov

- E-mail your question via the Internet to help@sti.nasa.gov

- Fax your question to the NASA Access Help Desk at (301) 621-0134

- Telephone the NASA Access Help Desk at (301) 621-0390

- Write to:

NASA Access Help Desk NASA Center for AeroSpace Information 7121 Standard Drive Hanover, MD 21076 
NASA/TM-2000-210250

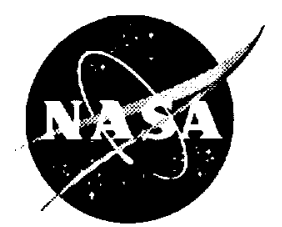

\section{Experimental Replication of an Aeroengine Combustion Instability}

J.M. Cohen, J.R. Hibshman, W. Proscia, T.J. Rosfjord and B.E. Wake United Technologies Research Center, East Hartford, Connecticut

J.B. McVey

jbScienceS, Glastonbury, Connecticut

J. Lovett and M. Ondas

Pratt \& Whitney, West Palm Beach, Florida

J. DeLaat and K. Breisacher

Glenn Research Center, Cleveland, Ohio

Prepared for the

45th International Gas Turbine and Aeroengine Technical Congress sponsored by the American Society of Mechanical Engineers

Munich, Germany, May 8-11, 2000

National Aeronautics and

Space Administration

Glenn Research Center 


\section{Acknowledgments}

This study was funded by the NASA Glenn Research Center. The authors would like to thank the following for their contributions to this effort: Mr. Saumil Shah of Pratt \& Whitney, Mr. Paul Hamel, Dr. Donald Hautman,

Ms. Andrea Karalus and Mr. James Tracy of United Technologies Research Center, and

Mr. Kestutis Civinskas of NASA Glenn.

Available from

NASA Center for Aerospace Information

7121 Standard Drive

Hanover, MD 21076

Price Code: A03
National Technical Information Service 5285 Port Royal Road Springfield, VA 22100 Price Code: A03 


\title{
EXPERIMENTAL REPLICATION OF AN AEROENGINE COMBUSTION INSTABILITY
}

\author{
J.M. Cohen, J.R. Hibshman, W. Proscia, T.J. Rosfjord, B.E. Wake \\ United Technologies Research Center \\ East Hartford, Connecticut \\ J.B. McVey \\ jbSciences \\ Glastonbury, Connecticut \\ J. Lovett, M. Ondas \\ Pratt \& Whitney \\ West Palm Beach, Florida \\ J. DeLaat, K. Breisacher \\ National Aeronautics and Space Administration \\ Glenn Research Center \\ Cleveland, Ohio
}

\begin{abstract}
Combustion instabilities in gas turbine engines are most frequently encountered during the late phases of engine development, at which point they are difficult and expensive to fix. The ability to replicate an engine-traceable combustion instability in a laboratory-scale experiment offers the opportunity to economically diagnose the problem (to determine the root cause), and to investigate solutions to the problem, such as active control. The development and validation of active combustion instability control requires that the causal dynamic processes be reproduced in experimental test facilities which can be used as a test bed for control system evaluation. This paper discusses the process through which a laboratory-scale experiment was designed to replicate an instability observed in a developmental engine. The scaling process used physically-based analyses to preserve the relevant geometric, acoustic and thermo-fluid features. The process increases the probability that results achieved in the single-nozzle experiment will be scaleable to the engine.
\end{abstract}

\section{INTRODUCTION}

Aggressive performance and emissions goals for aeroengine gas turbine combustors have led to the development of combustor concepts that may operate closer to static and dynamic stability boundaries. Lean, direct-injection combustors under development share many features with the lean, premixed combustors used in stationary gas turbines, in which combustion instabilities are widely observed.
In order to minimize development costs and time, it is critical to possess the ability to evaluate the dynamic behavior of a combustor design during the component-development phase, thereby mitigating the need for expensive full-scale engine testing late in the development cycle. Solutions to combustion instability problems, such as active and passive controls, can be evaluated and developed more quickly in a laboratory-scale experiment, enabling a faster transition of technology into production engines.

Laboratory- or component-scale testing of developmental combustor concepts is standard practice in the aircraft gasturbine industry, using single-nozzle flame tubes, single- and multi-nozzle sectors and full-annular combustor rigs. The gas turbine community has developed an experience base regarding the fidelity with which such test rigs must replicate engine design details in order to characterize the emissions and operability characteristics of engine combustors. At this time there is no proven methodology for replicating enginescale combustor dynamics in laboratory-scale rigs. The challenge in designing laboratory-scale combustion dynamics experiments is to replicate the engine dynamic environment in as simple (low-cost) an apparatus as possible. Recent published work suggests that bulk mode and longitudinal mode instabilities can be replicated in single-nozzle rigs. Cohen et al (1999) and Hibshman, et al (1999) performed active instability control experiments in single-nozzle and sector combustors that reproduced a bulk-mode instability observed in a lean, premixed industrial combustor. Paschereit 
et al (1999) have developed a sub-scale combustor in which the boundary conditions at the inlet and exit ends can be varied to impose a desired acoustic mode. No relevant work has been published on replication of tangential modes in multi-nozzle sector or configurations other than full annular combustors.

While the aforementioned investigators have shown that it is possible to create a realistic, laboratory-scale combustion dynamics experiment, the scaling processes through which these experiments can be designed have not been described with sufficient specificity to allow the methodology to be adopted by the technical community at large. In order for the results of sub-scale experiments to be useful to engine designers, there must be a system in place to translate those results to engine-scale. This paper discusses such a process, involving the following steps:

1. Analysis of dynamic data from the subject engine to determine characteristics of instability: frequency, amplitude, and sensitivity to changes in hardware configuration and operating conditions.

2. Acoustic analysis of the engine in order to determine acoustic modes associated with instability.

3. Conceptual design of a single-nozzle experiment, reproducing the engine's acoustic environment and replicating the relevant dynamic processes, as determined in steps 1 and 2.

4. Acoustic analysis of sub-scale experiment to determine its fundamental acoustic modes in order to confirm similarity with those observed in the engine.

5. Test of the finalized laboratory-scale experiment and comparison of data to analyses and engine data.

This paper presents the application of this process to an example problem, beginning with the analysis of an enginetraceable instability and culminating in the comparison of the lab-scale results to those from the engine

\section{ENGINE PROBLEM ANALYSIS}

The sample problem that was selected for this effort was a combustion instability that was observed during the development phase of a high-performance aero-engine that employed a full-annular combustor with 24 fuel nozzles. The frequency of the instability varied from about $420 \mathrm{~Hz}$ at lowpower conditions to about $580 \mathrm{~Hz}$ at high-power conditions, as shown in Fig. 1. At a mid-power operating point, corresponding to that used for the analytical phase of this study, the frequency of the instability was $525 \mathrm{~Hz}$. The magnitude of the pressure oscillations resulting from the instability were sufficient to cause unacceptable vibratory stresses in the turbine component of the engine
Passive means of reducing the magnitude of the pressure oscillations were developed during engine testing. This series of tests was able to detect a notable difference in the pressure oscillation magnitude when the fuel nozzle /air swirler design was changed. This led to the conclusion that the nozzle/swirler were important contributors to the instability mechanism.

To test this conclusion, a limited series of non-reacting experiments were conducted (Anderson, et al, 1998) to determine the acoustic and fluid mechanic response characteristics of the air swirlers that were used in the engine tests. The aim of these experiments was to measure differences in the responses of the air swirler / fuel injector designs that might explain their behavior in engine tests. It was found that the air swirlers associated with the largest pressure oscillations exhibited a preferential response to air flow perturbations in the frequency range between $300 \mathrm{~Hz}$ and $500 \mathrm{~Hz}$. Air swirlers that performed better in the engine did not exhibit this phenomenon in the non-reacting tests.

While fast-response combustor pressure data were acquired during the engine tests, they were acquired at a limited number of locations. For this reason, it was difficult to draw any significant conclusions about the nature of the instability purely from the engine data. The analyses described in the next section of this paper were used to augment and interpret the engine data. The combination of the engine data, the acoustic analyses and the non-reacting swirler/injector characterization provided the basis for replicating the problem in a single-nozzle combustor rig.

\section{Analysis of Engine Acoustics}

A quasi-1D unsteady Euler analysis (Wake et al., 1996) was used to predict the bulk and longitudinal modes of the engine combustor. The one-dimensional Euler equations were solved with area variation and modeled source terms to account for mass addition, heat addition and pressure losses.

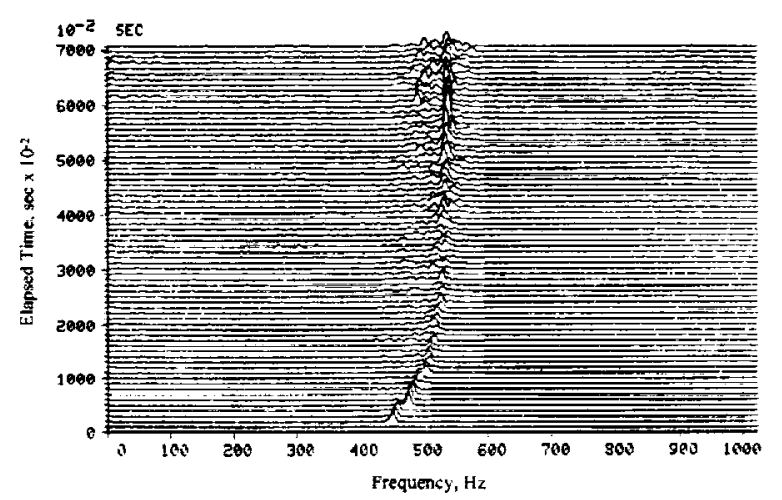

Figure 1. "Waterfall" plot of combustor pressure spectra from an engine test, showing evolution of the instability during an acceleration event. 
The resonant acoustic frequencies of the combustor were determined by solving for the unsteady time-accurate response of the system and monitoring the fluctuating pressure at a specified location. The analysis can be used to examine the sensitivity of the frequency and pressure amplitude to system parameters such as physical dimensions, temperature distribution, Mach number, flow rate and pressure drop. The solver was first used to compute the steady-state results, and then unsteady results were obtained by forcing the system. Forcing was accomplished by adding an unsteady component to the heat release. Two types of forcing signals were used: 1) broadband white-noise distributed forcing, and 2) swept sine forcing at a fixed frequency. The magnitude of the heat release forcing was $10 \%$ of the mean heat release rate. The resulting pressure response indicated the frequency dependence of the combustion system.

It should be recognized that this analysis is useful for its intended role of the determination of acoustic modes. The analysis does not attempt to incorporate the physics of the interaction of the fluid mechanics/acoustics with the heat release (effects of flame shape variation, local fuel/air variations, etc.) and therefore is not capable of predicting the absolute magnitude of the pressure response. The approach demonstrated in this paper will show that it is, however, a satisfactory tool for evaluating test rig acoustic characteristics for different combustion dynamics experiments.

Quasi-1D Euler calculations were conducted for the engine configuration at an intermediate operating condition: $\mathrm{T} 3=771^{\circ} \mathrm{F}(684 \mathrm{~K})$ and $\mathrm{P} 3=200 \mathrm{psia}(1.2 \mathrm{MPa})$. The engine geometry was converted into a one-dimensional description of area vs. axial position as shown by the dashed line in Fig. 2 , which shows the distributions for both the engine and the rig (to be discussed later). The geometry used included an inlet plenum, the engine prediffuser, diffuser plenum, the cowl or hood, the swirler, the combustor liner and turbine vanes. The combustor lies between $x=0$ and 9.25 in. Beyond the turbine

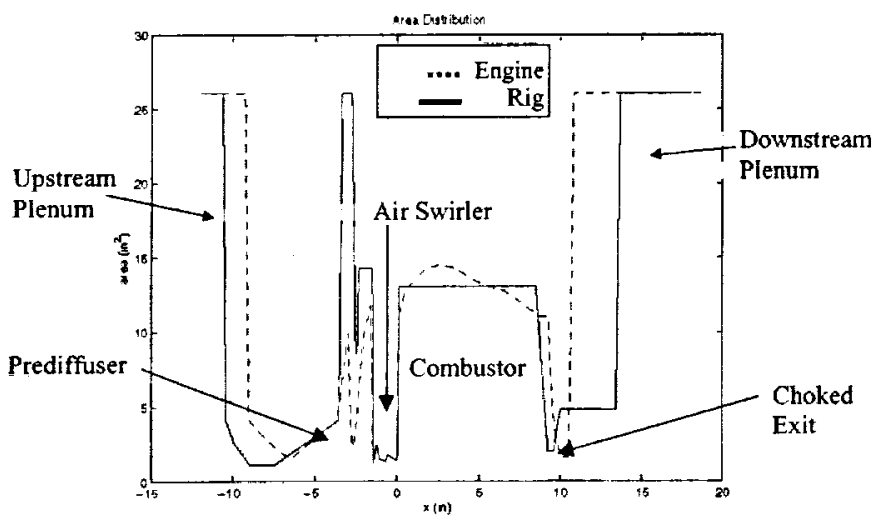

Figure 2. Cross-sectional area vs. axial position for quasi10 Euler model.

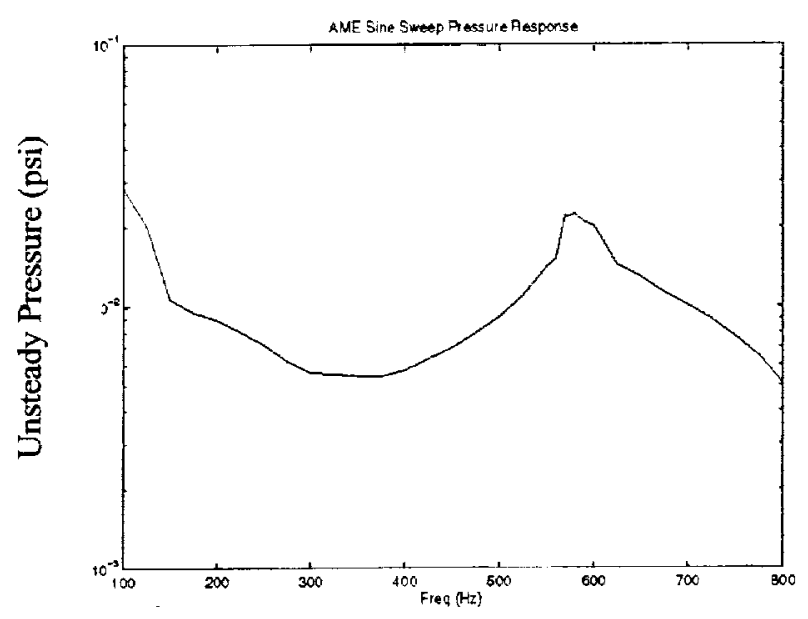

Figure 3. Computed power spectrum of combustor pressure for engine configuration with $100-800 \mathrm{~Hz}$ swept-sine forcing of heat release.

vane exit, the area was expanded rapidly to create a plenum dump. The boundary conditions used were constant total pressure at the inlet plenum and constant static pressure at the exit plenum.

The acoustic response of the system was obtained by swept-sine forcing of the entire heat release distribution. The fluctuation levels imposed on the heat release were $10 \%$ of the mean. The unsteady pressure amplitude at the $x=3$ in. location in the combustor ( 3 in. downstream of the combustor dump plane) was used to determine the pressure response. This location was chosen because it roughly aligned with the centroid of the presumed heat-release distribution. The sweptsine response is shown in Fig. 3 and indicates a resonance at approximately $575 \mathrm{~Hz}$. The width of the amplitude response peak indicates a large amount of damping. However, the width of the response also indicates a broad range of frequencies over which the system may be susceptible to combustion instability.

These results indicated a longitudinal mode in the combustor near $575 \mathrm{~Hz}$, near the observed frequency of about $525 \mathrm{~Hz}$. The pressure mode shape for this mode is shown in Fig. 4. The mode represents a full-wave solution to the system equations with zero unsteady pressure specified at each end. Given the high impedance at each end due to the high Mach number boundaries, the mode shape can also be interpreted as a half-wave across the diffuser-combustor domain with closed ends. Note there is a pressure node apparent at the air swirler/fuel injector $(x=0)$. The calculated fluctuating pressure in the diffuser was $180 \mathrm{deg}$. out of phase from the pressure in the combustor. It is believed that this was the basic acoustic mode that occurred in the engine configuration instability. 
Although tangential acoustic modes exist in the full-annular engine combustor, analysis of the engine data and twodimensional Euler results have indicated that they are not associated with the observed instability.

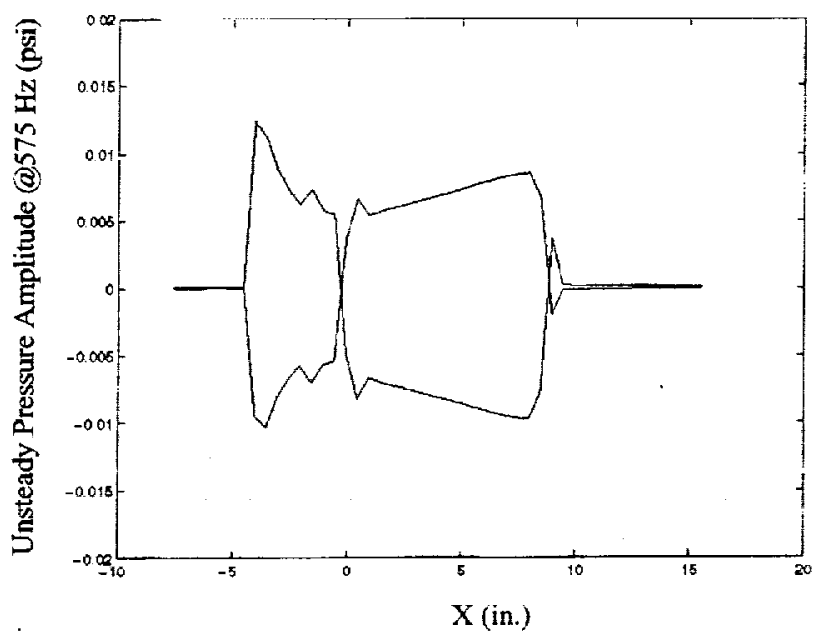

Figure 4. Computed pressure mode shape for $575 \mathrm{~Hz}$ mode for the engine configuration at evaluation point conditions.

\section{SUB-SCALE EXPERIMENT DESIGN}

\section{Test Apparatus Features}

Based on prior experience (Peracchio et al, 1998) the test rig design approach incorporated the following guidelines:

A. Use of full-scale fuel preparation sub-components fuel nozzles, air swirlers)

Prior evaluations (Anderson et al, 1998) indicated that the prototype injector/swirler exhibited an enhanced response near the $525 \mathrm{~Hz}$ frequency observed in the engine data so it was important to utilize that precise design. While reduced-size hardware may be of interest in order to minimize facility requirements, this approach was not taken, due to the introduction of uncertainties associated with reduced-scale flows.

B. Reproduction of the longitudinal acoustic behavior

The critical elements in this regard were the combustor, the diffuser, the pre-diffuser, and the cowl (hood) which guided the diffuser air to the fuel nozzle. Table I shows a comparison of the geometric features of the annular engine burner with those of the rig. Here, "shroud" refers to the region between the combustor liner and combustor casing. Crosssectional areas were chosen to replicate associated volumes and expansion/contraction ratios.
Table I-Comparison of engine and rig acoustic features.

\begin{tabular}{|l|c|c|}
\hline \multicolumn{1}{|c|}{ Feature } & Engine & Rig \\
\hline $\begin{array}{l}\text { Combustor Volume per Injector } \\
\left.\text { (in }{ }^{3} / \mathrm{cc}\right)\end{array}$ & $113 /$ & $108 /$ \\
& 1851 & 1770 \\
\hline Combustor Length (in./cm) & $8.5 / 21.3$ & $8.5 / 21.3$ \\
\hline Shroud Volume per Injector & $129.3 /$ & $103.4 /$ \\
in $\left.^{3} / \mathrm{cc}\right)$ & 2119 & 1695 \\
\hline Nominal Shroud Height (in./cm) & $1.2 / 3.0$ & $0.80 / 2.0$ \\
\hline Diffuser length $($ in./cm) & $2.7 / 6.9$ & $2.7 / 6.9$ \\
\hline Pre-diffuser Length $(\mathrm{in} . / \mathrm{cm})$ & $3.9 / 9.9$ & $3.9 / 9.9$ \\
\hline
\end{tabular}

C. Acoustic isolation of the combustor from facility air piping

A venturi was used to choke and meter the inlet air flow. Since the isolation provided by the sonic throat condition was desired over a range of conditions, the venturi was designed to be underexpanded, resulting in a normal shock at a distance of 1.38 in. $(3.5 \mathrm{~cm})$ downstream of the venturi throat. The upstream boundary was largely established by the normal shock and the sudden expansion of the flow at the prediffuser dump. The downstream boundary was defined by using a choked exhaust nozzle at the station occupied by the first turbine inlet vane.

D. Reproduction of the air flow distribution, pressure drops and flow damping characteristics

The pressure drops and airflow splits used in the engine were duplicated. That is, the fractions of air used for liner cooling and for primary and dilution air were reproduced. Designing for equivalent damping is important to achieving similar instability amplitudes between the test rig and the engine. The resistive damping of the system was maintained by replicating the system's pressure drops. Reproducing the splits between the different air flows replicates the distribution of stoichiometry and heat release rate within the combustor. The shroud height (distance between combustor liner and pressure vessel wall) was also preserved in order to preserve the shroud air velocity.

\section{E. Design for testing at engine operating conditions}

The instability observed in the engine occurred over a range of test conditions. A single "Evaluation Point" was chosen at 200-psia (1.2 MPa) combustor pressure, an entrance temperature of $771^{\circ} \mathrm{F}(684 \mathrm{~K})$, and combustor fuel-air ratio of approximately 0.03 . This mid-power point on the engine operating curve did not correspond to the highest-amplitude pressure oscillations, but was the maximum power level achievable given the facility limitations. All analyses were conducted at these conditions. Operating at 
reduced conditions with full-scale hardware can change the operating characteristics of the components (pressure drops, atomization, etc.).

The final consideration was whether to utilize an apparatus with a simple cylindrical cross-section burner or an apparatus having a cross-section representative of $1 / 24$ of the 24-nozzle engine burner - i.e., a 'single sector' burner. A circular cross-section was employed, as this represented the lower-cost, higher-strength approach. The number and size of the combustion and dilution air holes was adjusted to provide proper penetration of these air jets.

The configuration of the test section is illustrated in Fig. 5. Provisions for high-response pressure transducers and for gas sampling (not reported herein) were incorporated.

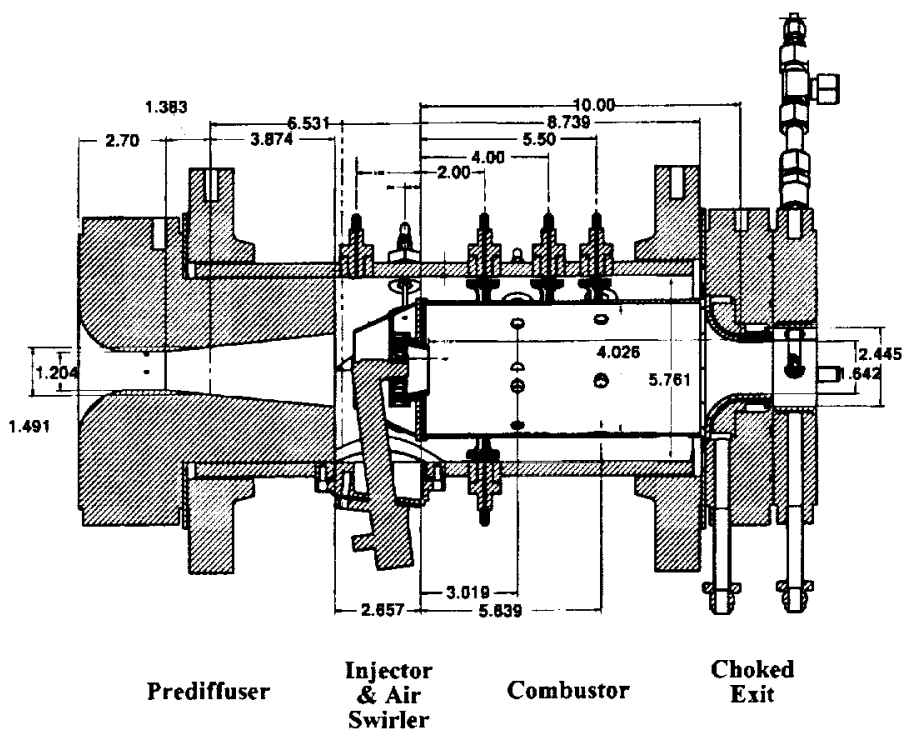

Figure 5. The combustor test section assembly. Dimensions are in inches.

Three transducer bosses, equally spaced around the circumference, were located in the primary combustion zone. One was located in the secondary zone, and one in the dilution zone. Floating seals on the liner captured extension tubes attached to the pressure-vessel-mounted transducers such that the pressures at the inside liner surface could be recorded. Bosses for shroud flow pressure measurements were provided at the location of the liner primary and dilution holes. Bosses for diffuser pressure measurements, upstream of the combustor, were also provided

PCB piezo-electric pressure transducers ( $\mathrm{P} / \mathrm{N}$ 124A21) were selected for this application based on demonstrated ability to withstand the severe environment encountered in the combustor and pre-diffuser (high temperature and pressure). Originally developed for measuring combustion instability in liquid rockets, they are capable of measuring \pm 250 psi. pressure fluctuations at frequencies between $0.5 \mathrm{~Hz}$ and 10 $\mathrm{kHz}$. Satisfactory durability was achieved by use of an integral water-cooled mounting fixture that maintained an acceptable temperature around the sensor. The liner pressure sensors communicated with the combustor through a 0.062 in. $(1.6 \mathrm{~mm})$-diameter, 0.83 in. $(2.1 \mathrm{~cm})$-long sensing tube. A 1000 psia nitrogen supply was used to purge the tube - the amount of purge flow rate was negligible. The 1/4-wave resonant frequency of the cavity within this tube was far above the frequency range of interest in this experiment. Analog data were low-pass filtered at $2 \mathrm{kHz}$ and digitally sampled at 5 $\mathrm{kHz}$ using a simultaneous sample-hold data acquisition system.

\section{Analysis of Single-Nozzle Rig Acoustics}

The single-nozzle combustor rig design was established to preserve the axial lengths and cross-sectional areas of the engine configuration relative to a single nozzle. The area vs. axial position distribution was maintained approximately the same (ref. Fig. 2), but some variation existed due to differences in engine hardware and the axisymetric hardware to be used in the single-nozzle combustor. Airflow splits and pressure losses - swirler, bulkhead, liner, primary and dilution jets were also preserved by design. The inlet and exit of the rig were choked to acoustically isolate the system. The Euler models included inlet and exit plenums upstream and downstream of the choke points to allow constant total pressure and constant static pressure to be specified, respectively, as boundary conditions to be applied to the Euler code domain.

Quasi-1D Euler calculations were conducted for the baseline rig configuration at the evaluation point operating condition: $771^{\circ} \mathrm{F}(684 \mathrm{~K}), 200$ psia $(1.2 \mathrm{MPa})$. Swept-sine forcing over the frequency range from 100 to $800 \mathrm{~Hz}$ was applied to the heat release. The resulting power spectrum of the pressure response is shown in Fig. 6, indicating the

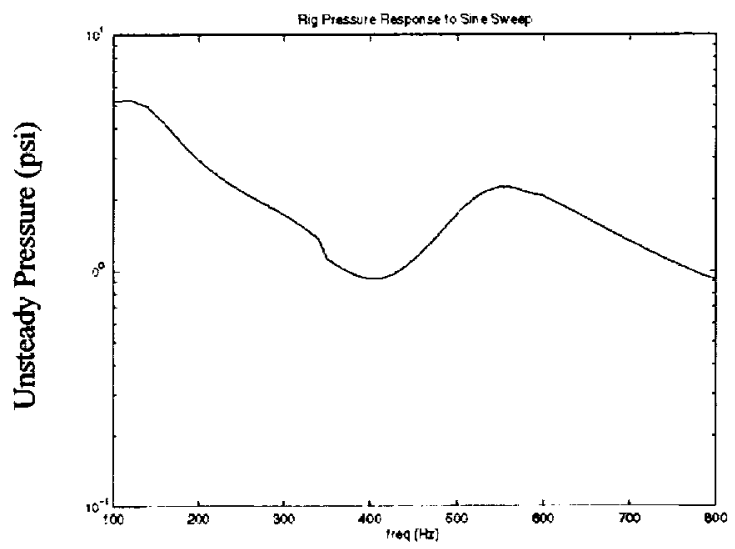

Figure 6. Computed power spectrum of combustor pressure at $x=3.0$ in. for the rig configuration. Quasi1D Euler code results for 100-800 Hz swept-sine forcing of heat release. 
presence of resonances at $\sim 115 \mathrm{~Hz}$ and $\sim 575 \mathrm{~Hz}$. The fluctuating levels imposed on the heat release were $10 \%$ of the mean. However, the level of forcing employed in the analysis is arbitrary, and within the linear response range, so that no significance should be attached to the absolute levels of the ordinates in Figs. 3 and 6.

Further analysis of the mode shapes associated with these resonances revealed that the low frequency $115 \mathrm{~Hz}$ mode was a first-order longitudinal mode where the diffuser and combustor were in phase. The primary mode of interest was the $575 \mathrm{~Hz}$ mode since the observed instability frequency in the engine was $525 \mathrm{~Hz}$. The pressure mode shape is shown in Fig. 7. The $575 \mathrm{~Hz}$ mode was essentially a half-wave longitudinal mode considering closed/closed acoustic boundary conditions from diffuser inlet to combustor exit. A pressure node appeared to occur at the air swirler/fuel injector location. The pressure in the diffuser was $180 \mathrm{deg}$. out of phase from the pressure in the combustor. Note there was some activity downstream of the combustor exit, but calculations performed with varying exit plenum length did not indicate significant changes in the resonant frequency.

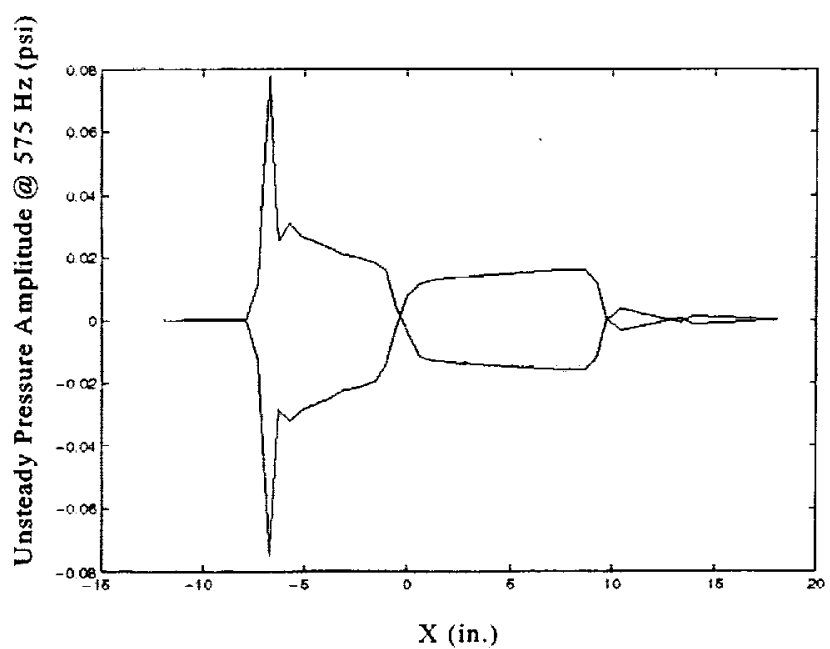

Figure 7. Computed pressure mode shape for the $575 \mathrm{~Hz}$ mode for the rig configuration at evaluation point conditions.

The main conclusion drawn from the acoustic analyses is that the single-nozzle combustor rig configuration will have a longitudinal acoustic resonance at about $575 \mathrm{~Hz}$ that is very similar to the mode observed in engine data and predicted by Euler analysis of the engine configuration.

\section{EXPERIMENTAL RESULTS}

The operating conditions of the combustor could be completely described by the following parameters: diffuser air pressure (P3), diffuser air temperature (T3) and combustor fuel/air ratio (f/a). Values for each of these parameters were chosen to correspond to three different engine operating conditions. These are shown in Table II. The fuel/air ratio referred to is that estimated at the exit of the combustor and accounted for all of the air flowing into the combustor through the air swirler, primary and dilution holes and liner/bulkhead cooling passages. It was not possible to vary the test parameters independently because of the choked, fixed-area combustor exit.

Table II - Test conditions corresponding to engine operating points. Evaluation-point conditions are in italics.

\begin{tabular}{|c|c|c|}
\hline $\begin{array}{c}\text { Inlet Air } \\
\text { Pressure, P3 } \\
\text { (psia/MPa) }\end{array}$ & $\begin{array}{c}\text { Inlet Air } \\
\text { Temperature, T3 } \\
\text { ('F } / \mathbf{K})\end{array}$ & $\begin{array}{c}\text { Fuel/Air } \\
\text { Ratio }\end{array}$ \\
\hline $70 / 0.48$ & $500 / 533$ & 0.016 \\
\hline $110 / 0.76$ & $600 / 589$ & 0.024 \\
\hline $175 / 1.21$ & $771 / 684$ & 0.030 \\
\hline
\end{tabular}

For the evaluation point operating conditions, an instability was observed at a frequency of $566 \mathrm{~Hz}$ (see Fig. 8). The amplitude of this mode at these conditions was $+/-0.39$ psi $(2.7 \mathrm{kPa})$. The unsteady pressure results presented here are from the transducer located at $2.0 \mathrm{in}$. $(5.1 \mathrm{~cm}$.) downstream of the combustor bulkhead. The amplitude of the instability increased with increasing fuel/air ratio for fixed P3 and T3. At higher fuel/air ratios, the overall RMS pressure fluctuations were dominated by this single tone. There was significant noise generated in the $100-300 \mathrm{~Hz}$ range, although none of it was particularly coherent.

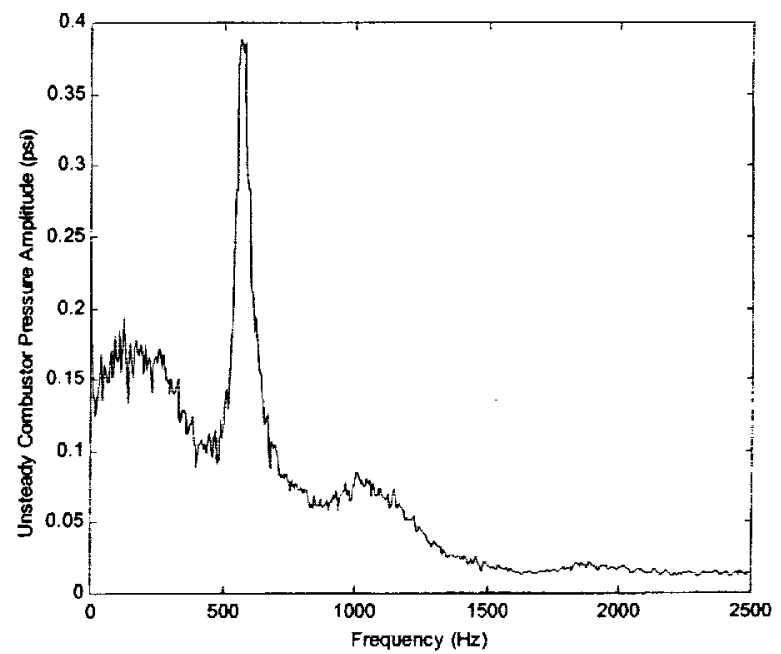

Figure 8. Measured power spectrum of unsteady combustor pressure at $x=2.0$ in. for Evaluation Point operating conditions, showing resonance at $566 \mathrm{~Hz}$, with an amplitude of 0.39 psi (0.78 psi p-p). 


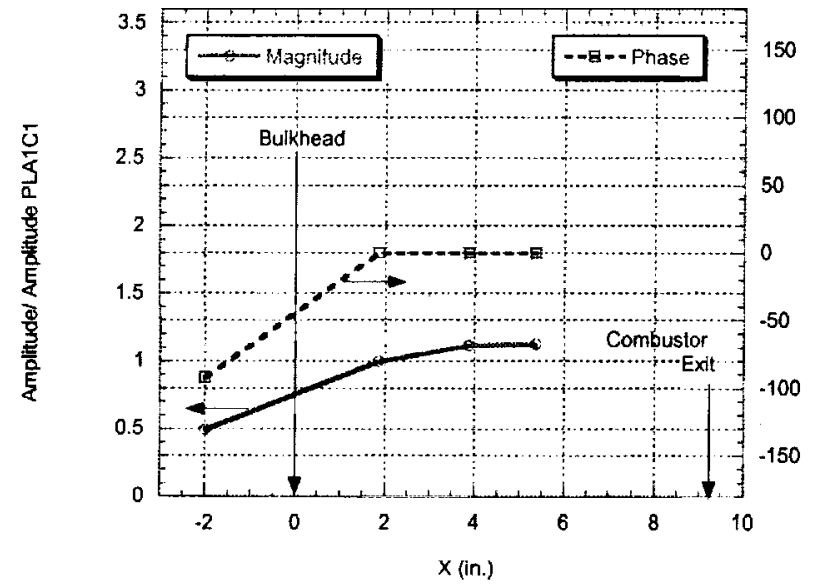

Figure 9. Measured distribution of $566 \mathrm{~Hz}$ mode, showing magnitude and phase referenced to pressure measurement PLA1C1 at $x=2.0$ inches downstream of the combustor bulkhead.

Figure 9 shows the spatial distribution of the unsteady pressure at three locations within the combustor and one location in the diffuser region upstream. Within the combustor, there was no phase difference between measurements at different axial stations, and only small differences in amplitude. Significant $566 \mathrm{~Hz}$ signal was also apparent upstream of the combustor, which lagged the combustor pressure by 92 degrees in phase and was smaller in amplitude by a factor of 2 . There were no phase or magnitude differences (at $566 \mathrm{~Hz}$ ) between pressure measurements at equivalent axial, but differing circumferential stations,

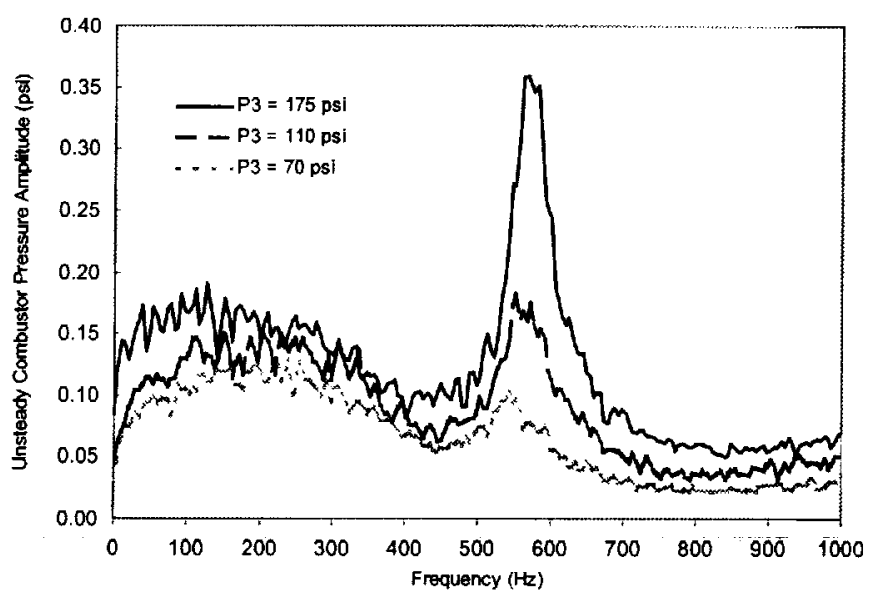

Figure 10. Power spectra of unsteady combustor pressure at three operating conditions corresponding to those in Table II, showing decreasing amplitude of $566 \mathrm{~Hz}$ mode with decreasing power level. consistent with a longitudinal acoustic mode. The unsteady pressure in the shroud, just outside the dilution holes was a factor of 2 smaller than that in the combustor and lagged the combustor pressure by approximately 40 degrees.

This mode was also observed at the other two, lowerpower, operating conditions, although at smaller amplitudes and lower frequencies, as shown in Fig. 10.

\section{ANALYSIS OF RESULTS}

Comparison with Analytical Results

The experimental results can be compared to the analytical results by referencing Fig. 6, which shows the predicted pressure spectrum, and Fig. 8, which shows the measured pressure spectrum. Recall the Euler code model predicted broad acoustic resonances at about $575 \mathrm{~Hz}$ and 115 $\mathrm{Hz}$. In the experiment, an instability centered near $566 \mathrm{~Hz}$ was observed, and there was some incoherent activity indicated near $100-200 \mathrm{~Hz}$. Thus, the agreement appears to be good. The mode shape measured in the experiment was of limited spatial resolution and showed little spatial variation of unsteady pressure amplitude or phase within the combustor chamber itself for the $566 \mathrm{~Hz}$ mode (ref. Fig. 9). This was consistent with the mode shape of the $575 \mathrm{~Hz}$ mode predicted by the Euler code (ref. Fig. 7). Note both results did indicate a slight decrease in amplitude towards the upstream end of the combustion chamber. The Euler code prediction indicated the unsteady pressure in the diffuser upstream of the combustor would be $180^{\circ}$ out-of-phase with the combustor pressure. The experimental results indicated a significant phase shift in the diffuser section, lagging the combustor pressure by about 90 degrees at $566 \mathrm{~Hz}$. This discrepancy is likely associated with the 1-D limitations of the model. For example, it is expected that some level of coupling to the outer shroud passage would occur which is also coupled to the combustor via the air mixing holes. Therefore, some transition of the phase from inphase with the combustor outside the mixing holes to out-ofphase in the diffuser section is expected in the 3-D problem. The result could be a phase relation in the diffuser section between 0 and 180 degrees.

Note that, because the Euler code is essentially an acoustic calculation, it is fundamentally limited in its ability to calculate the amplitude of the pressure oscillations without the addition of a combustion / acoustic coupling model. In calculations for the engine using a constant relative forcing level, the Euler code indicated that both the frequency and amplitude of the instability should increase with increasing engine power level. This trend was validated with engine data and was also reproduced in the single-nozzle experiment (ref. Fig. 1 and Fig. 10). It is also encouraging that the damping mechanisms present in the calculations produced a broad peak at $575 \mathrm{~Hz}$, much like that seen in the experiment (see Fig. 10). 


\section{Comparison with Engine Data}

Figure 11 shows a comparison between the fluctuating pressure spectrum in the engine and the single-nozzle combustor at comparable operating conditions. Both data sets were acquired over 10 seconds, and were processed using the same techniques. The frequency of the "target" mode was reproduced within $12 \%$. The amplitude of this mode was matched within $3 \%$. The spectral peak was significantly narrower in the engine data, indicating a more coherent instability. The single-nozzle combustor also exhibited a higher overall level of noise in the signal, especially at frequencies below $350 \mathrm{~Hz}$.

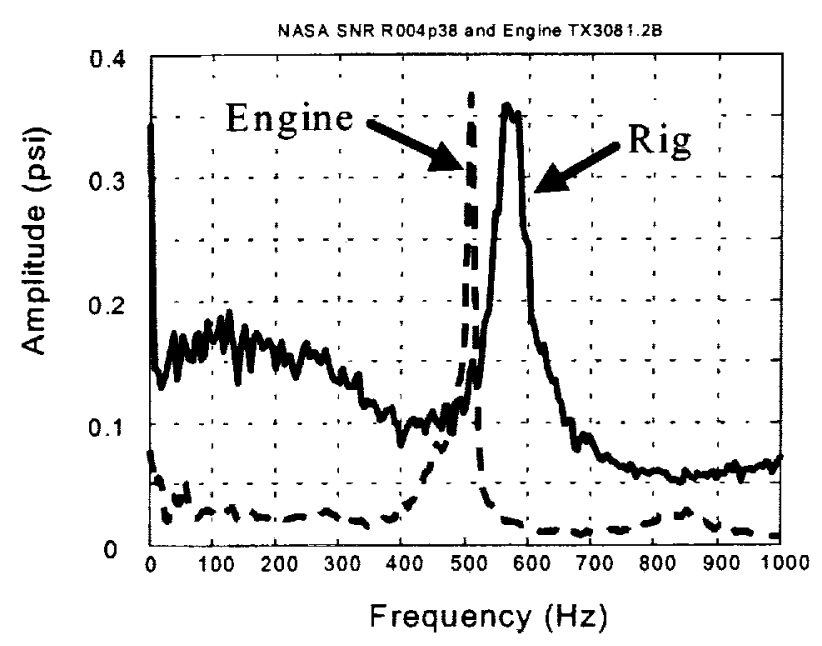

Figure 11. Comparison of engine and combustor rig pressure spectra for Evaluation-Point operation.

\section{CONCLUSIONS AND RECOMMENDATIONS}

A methodology for replicating longitudinal combustion instabilities observed in an aircraft engine in a single-nozzle test rig was successfully demonstrated. The experiment reproduced the frequency of the engine instability within $12 \%$ and its amplitude within $3 \%$.

Necessarily, the replication procedure must use both predictions from analytical tools and engineering judgements based on prior combustion dynamics studies. A relatively simple, quasi-one-dimensional Euler analysis is satisfactory for the prediction of the dynamics of longitudinal instabilities in geometrically complex burners.

The one-dimensional analytical acoustic tools applied in this program predicted the basic acoustic frequencies of both the engine and the rig within about $10 \%$, and supported a methodology to define a test rig with specific acoustic frequency characteristics. However, because the tool is a onedimensional analysis, it cannot capture all the dynamic features of this combustor. For example, as reported, it did not quantitatively predict the phase relationship between the combustor and diffuser. The development of an analytical tool that would include multi-dimensional capability to either identify other modes or include the influence of parallel acoustic paths (e.g., shroud) is recommended.

An extension of these tools to design sub-scale experiments in which instabilities associated with tangential acoustic modes would also be useful. Inclusion of acousticheat release coupling would also increase the tool's utility. Acoustic-heat release coupling models could provide a capability for further reductions in the scale of the experiment, in such parameters as geometric size, flow rates and operating pressure.

In summary, a methodology for design of laboratory combustors, which reproduce combustion instabilities observed in aircraft engine combustors, has been demonstrated. A realistic platform for the development and validation of active combustion instability control systems was constructed, and will be utilized in subsequent programs.

\section{BIBLIOGRAPHY}

Anderson, T.J., D.W. Kendrick and J.M. Cohen, "Measurement of Spray / Acoustic Coupling in Gas Turbine Fuel Injectors," AIAA Paper 98-0718, Presented at the $36^{\text {th }}$ AIAA Aerospace Sciences Meeting \& Exhibit, January 1998, Reno, NV.

Cohen, J.M., N.M. Rey, C.A. Jacobson and T.J. Anderson, "Active Control of Combustion Instability in a Liquid-Fueled Low-NO ${ }_{x}$ Combustor," ASME Journal of Engineering for Gas Turbines and Power, Vol. 121, No. 2, pp. 281-284, April 1999.

Hibshman, J.R., J.M. Cohen, A. Banaszuk, T.J. Anderson and H.A. Alholm, "Active Control of Combustion Instability in a Liquid-Fueled Sector Combustor," ASME Paper 99-GT-215, Presented at the International Gas Turbine and Aeroengine Congress \& Exposition, Indianapolis, IN, June 1999.

Paschereit, C.O., E. Gutmark and W. Weisenstein, "Control of Combustion Driven Oscillations by Equivalence Ratio Modulations," ASME Paper 99-GT-118, Presented at the International Gas Turbine and Aeroengine Congress \& Exposition, Indianapolis, IN, June 1999.

Peracchio, A. A., T. Rosfjord, J. McVey, T. Anderson, A. Banaszuk, J. Cohen, J. Hibshman, C. Jacobson, A. Khibnik, W. Proscia and N. Rey, "Active Control for Marine and LandBased Aeroderivative Gas Turbine Engines" Volume 1, DARPA Final Contractor Report, UTRC Report 98-16, December 1998.

Wake, B.E., D. Choi, G.J. Hendricks, "Numerical Investigation of Pre-Mixed Step-Combustor Instabilities," AIAA Paper 96-0816, Presented at the $34^{\text {th }}$ AIAA Aerospace Sciences Meeting \& Exhibit, January 1996, Reno, NV. 


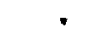




\begin{tabular}{|c|c|c|c|}
\hline \multicolumn{3}{|c|}{ REPORT DOCUMENTATION PAGE } & $\begin{array}{l}\text { Form Approved } \\
\text { OMB No. 0704-0188 }\end{array}$ \\
\hline \multicolumn{4}{|c|}{ 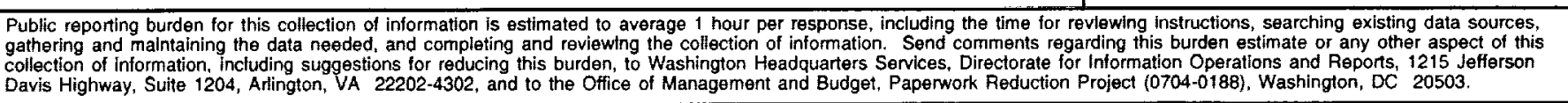 } \\
\hline 1. AGENCY USE ONLY (Leave blank) & $\begin{array}{r}\text { 2. REPORT DATE } \\
\text { August } 2000\end{array}$ & $3 . \mathrm{F}$ & $\begin{array}{l}\text { ID DATES COVERED } \\
\text { echnical Memorandum }\end{array}$ \\
\hline \multicolumn{3}{|c|}{$\begin{array}{l}\text { 4. TITLE AND SUBTITLE } \\
\text { Experimental Replication of an Aeroengine Combustion Instability }\end{array}$} & \multirow{2}{*}{$\begin{array}{l}\text { 5. FUNDING NUMBERS } \\
\text { WU-523-26-13-00 }\end{array}$} \\
\hline \multicolumn{3}{|c|}{$\begin{array}{l}\text { 6. AUTHOR(S) } \\
\text { J.M. Cohen, J.R. Hibshman, W. Proscia, T.J. Rosfjord, B.E. Wake, } \\
\text { J.B. McVey, J. Lovett, M. Ondas, J. DeLaat, and K. Breisacher }\end{array}$} & \\
\hline \multicolumn{3}{|c|}{$\begin{array}{l}\text { National Aeronautics and Space Administration } \\
\text { John H. Glenn Research Center at Lewis Field } \\
\text { Cleveland, Ohio } 44135-3191\end{array}$} & $\begin{array}{l}\text { 8. PERFORMING ORGANIZATION } \\
\text { REPORT NUMBER }\end{array}$ \\
\hline \multicolumn{2}{|c|}{$\begin{array}{l}\text { 9. SPONSORING/MONITORING AGENCY NAME(S) AND ADDRESS(E } \\
\text { National Aeronautics and Space Administration } \\
\text { Washington, DC 20546-0001 }\end{array}$} & & $\begin{array}{l}\text { 10. SPONSORINGMONITORING } \\
\text { AGENCY REPORT NUMBER } \\
\text { NASA TM-2000-210250 }\end{array}$ \\
\hline \multicolumn{4}{|c|}{$\begin{array}{l}\text { 11. SUPPLEMENTARY NOTES } \\
\text { Prepared for the 45th International Gas Turbine and Aeroengine Technical Congress sponsored by the American Society of Mechanical } \\
\text { Engineers, Munich, Germany, May 8-11, 2000. J.M. Cohen, J.R. Hibshman, W. Proscia, T.J. Rosfjord and B.E. Wake, United Technolo- } \\
\text { gies Research Center, } 411 \text { Silver Lane, East Hartford, Connecticut 06108; J.B. McVey, jbScienceS, } 223 \text { Cider Mill Road, Glastonbury, } \\
\text { Connecticut 06033; J. Lovett and M. Ondas, Pratt \& Whitney, P.O. Box 109600, West Palm Beach, Florida 33410; J. DeLaat and } \\
\text { K. Breisacher, NASA Glenn Research Center. Responsible person, John DeLaat, organization code 5530, (216) 433-3744. }\end{array}$} \\
\hline
\end{tabular}

12a. DISTRIBUTIONIAVAILABILITY STATEMENT 12b. DISTRIBUTION CODE

Unclassified - Unlimited

Subject Category: 01

Distribution: Nonstandard

This publication is available from the NASA Center for AeroSpace Information, (301) 621-0390.

13. ABSTRACT (Maximum 200 words)

Combustion instabilities in gas turbine engines are most frequently encountered during the late phases of engine development, at which point they are difficult and expensive to fix. The ability to replicate an engine-traceable combustion instability in a laboratory-scale experiment offers the opportunity to economically diagnose the problem (to determine the root cause), and to investigate solutions to the problem, such as active control. The development and validation of active combustion instability control requires that the causal dynamic processes be reproduced in experimental test facilities which can be used as a test bed for control system evaluation. This paper discusses the process through which a laboratory-scale experiment was designed to replicate an instability observed in a developmental engine. The scaling process used physically-based analyses to preserve the relevant geometric, acoustic and thermo-fluid features. The process increases the probability that results achieved in the single-nozzle experiment will be scaleable to the engine.

\begin{tabular}{|l|l|}
\hline 14. SUBJECT TERMS \\
Aircraft engines; Engine control; Combustion control; Co \\
\hline $\begin{array}{c}\text { 17. SECURITY CLASSIFICATION } \\
\text { OF REPORT } \\
\text { Unclassified }\end{array}$ & $\begin{array}{c}\text { 18. SECURITY CLASSIFICATION } \\
\text { OF THIS PAGE } \\
\text { Unclassified }\end{array}$ \\
\hline
\end{tabular}

19. SECURITY CLASSIFICATION OF ABSTRACT

Unclassified

\begin{tabular}{|c|c|}
\hline \multirow[b]{2}{*}{ bustion stability; Control } & $\begin{array}{c}\text { 15. NUMBER OF PAGES } \\
14 \\
\end{array}$ \\
\hline & $\begin{array}{r}\text { 16. PRICE CODE } \\
\mathrm{AO} 3\end{array}$ \\
\hline $\begin{array}{l}\text { 19. SECURITY CLASSIFICATION } \\
\text { OF ABSTRACT } \\
\text { Unclassified }\end{array}$ & 20. LIMITATION OF ABSTRACT \\
\hline
\end{tabular}

Standard Form 298 (Rev. 2-89)

Prescribed by ANSI Std. Z39-18 298-102 